\title{
Uma tradução do poema Moretum em hexâmetro dactílico português ${ }^{1}$ \\ A Translation of the Poem Moretum into Portuguese Hexameters
}

\author{
Marina Grochocki² \\ e-mail: marinagrochocki@gmail.com \\ orcid: http://orcid.org/0000-0002-6591-3383
}

DOI: http://dx.doi.org/10.25187/codex.v6i1.12249

Resumo: O poema pseudo-virgiliano Moretum tem sido cada vez mais abordado pela crítica contemporânea não apenas em relação à questão da autoria, mas sim das suas relações intertextuais com outros textos clássicos. $\mathrm{O}$ artigo busca traçar um breve panorama desses estudos mais recentes, apontando para o leitor quais as possíveis interpretações das relações entre Moretum e os autores Virgílio e Ovídio. Para isso, são elencadas brevemente algumas características comuns ao poema do Apêndice Virgiliano e às obras de Virgílio, assim como outras são comparadas a uma cena de theoxenia em Ovídio. Ao fim, apresenta-se o texto original em latim, problematizando algumas de suas passagens mais incertas, e uma proposta de tradução do poema para o português. Nessa tradução, utilizamos o modelo chamado "hexâmetro datílico em português", que busca emular através de oposição entre sílabas átonas e tônicas na língua portuguesa o ritmo dos hexâmetros datílicos.

Palavras-chave: Apêndice Virgiliano; Virgílio; Ovídio; Moretum

Abstract: Recent scholarship on the pseudo-Virgilian Moretum has discussed more than its authorship. Nowadays, it focuses instead on the poem's intertextual relationships with other classical texts. This paper aims to offer a general view of these recent studies, addressing some possible interpretations for the interrelationships between the Moretum and authors such as Vergil and Ovid. It enumerates a few common features of the Appendix Vergiliana poem and Vergil's works and compares other characteristics to a theoxeny scene in Ovid. At the end we present the Latin text, discuss some of its corrupt passages and give a translation of the poem into Portuguese. In this translation, we use the so-called "hexameter in Portuguese" model, which tries to emulate the rhythm of the Latin hexameters through the contrast between stressed and unstressed syllables in Portuguese.

Keywords: Appendix Vergiliana; Vergil; Ovid; Moretum

1 Este trabalho apresenta parte de um dos capítulos de minha dissertação de mestrado em andamento na Universidade Federal do Paraná, intitulada Estudo e tradução do Apêndice Virgiliano. A proposta é traduzir e analisar cada um dos poemas que compõe a coletânea, segundo o arranjo proposto por Clausen (1966). Assim, deixo os devidos agradecimentos ao orientador, Prof. Dr. Alessandro Rolim de Moura, e ao Prof. Dr. Guilherme Gontijo Flores, que apontou melhorias a serem feitas na tradução.

${ }^{2}$ Mestranda em Letras - Estudos Literários, na Universidade Federal do Paraná, Brasil, sob a orientação do Prof. Dr. Alessandro Rolim de Moura. 


\section{iจฺ}

\section{Sobre o poema}

Atualmente, o poema Moretum dificilmente pode ser considerado como uma obra de Virgílio. Ele aparece entre os manuscritos do Apêndice Virgiliano apenas no século IX, no catálogo de Murbach (PEIRANO, 2012, p. 78), não sendo citado por Donato e Sérvio junto dos outros supostos poemas da juventude do mantuano. Mesmo assim, Moretum é mantido até hoje em edições mais recentes da coletânea de poemas (ver, por exemplo, a edição de Salvatore, 1997).

Apesar de não haver nenhum indício decisivo para a questão da autoria3 ${ }^{3}$, é inegável que estamos diante de um autor que conhecia bem alguns dos poetas do I século a.C., como Virgílio e Ovídio. Se, por um lado, o estilo da narrativa de Moretum se mostra diferente dos que encontramos em Virgílio4, há de qualquer modo um diálogo com suas três grandes obras. Justamente a sua proximidade temática com as Bucólicas e com as Geórgicas pode ser um dos motivos para que a obra fosse, em determinado momento, atribuída a Virgílio.

O poema descreve com certa riqueza de detalhes como é o início do dia de Símulo, um modesto agricultor. Grande destaque é dado ao preparo do pão e do alimento moretum (uma

\footnotetext{
${ }^{3}$ Já foi inclusive levantada a hipótese de que Moretum seria, na verdade, uma tradução de um poema grego escrito por Partênio (ELLIS, 1906, p. 13). Segundo Macróbio (5, 17, 18), Partênio foi professor de Virgílio, o que poderia favorecer a ideia de Moretum como uma tradução feita por Virgílio de um poema de seu mentor. Uma hipótese mais atual é de que talvez estejamos diante de um Vergilius impersonatus (HÖSCHELE, 2005, pp. 267-269), isto é, de um poeta que escreveu conscientemente algo que Virgílio poderia ter escrito em alguma das fases da sua vida. Qual a intenção ao se passar por Virgílio não é necessariamente clara, podendo ser tanto para enganar o leitor quanto apenas para diverti-lo. É possível inclusive supor que parte do público interpretasse o poema como uma brincadeira e outra parte como um texto que realmente fora escrito por Virgílio.

${ }^{4}$ Cf., por ex., Perutelli (1983, p. 13).
} 
mistura de queijos, ervas e alho), assim como também à descrição da pequena horta de Símulo. Se alguns críticos, como Rand (1919, p. 178), consideram essa escolha temática uma falha do poema, já que ele não teria refinamento poético e apenas narraria algo demasiado realista, isso está longe do correto. Poderíamos citar alguns dos recursos estilísticos utilizados pelo poeta para comprovar nossa visão, como a estrutura da narrativa: as duas principais cenas (o preparo do pão, vv. 38-50, e o preparo do moretum, vv. 92-116) ocorrem respectivamente antes e depois das duas principais digressões, possuindo paralelos significativos entre elas 5 , mas ao mesmo tempo tendo diferenças que não as tornam repetitivas (PERUTELLI, 1983, p. 24).

Se a temática de um simples homem do campo, que inclusive canta enquanto trabalha (v. 29), lembra as Bucólicas, no entanto, é possível perceber que a situação em que o homem rústico se encontra em muito delas difere. Não existe em Virgílio um tom realista como vemos em Moretum. Certa comparação poderia ser feita com Teócrito ${ }^{6}$, já que no Idílio 10 (vv. 21-23) o ceifador Mílon sugere que Buceu deve cantar para aliviar seu sofrimento e prosseguir com seu trabalho. Porém, a diferença entre as naturezas do sofrimento de Símulo e Buceu é clara: enquanto Símulo enfrenta uma luta contra sua própria fome, Buceu lamenta um amor malfadado.

Do mesmo modo, a prolongada descrição sobre uma prática dos trabalhadores rurais - a preparação para um dia de trabalho - poderia evocar as Geórgicas. A descrição da horta de Símulo se mostra relacionada à do jardim de um velho da Cilícia (Geórgica 4, vv. 116-148). Em ambos os casos, a dedicação dos donos faz com que a horta seja produtiva. Elas possuem papel

\footnotetext{
${ }^{5}$ Por ex., a menção da divisão do trabalho entre as duas mãos (v. 24ff e v. 98f) e a circularidade do movimento realizado (v. 26 e vv. 101, 110).

${ }^{6}$ Cholmeley (1909, pp. 58-60) é um dos críticos que afirma que Teócrito foi o poeta bucólico mais realista e que as características artificiais da tradição bucólica apenas apareceram na poesia subsequente.
} 
fundamental no sustento (alimentar e/ou financeiro) de Símulo e Coriciano (PERUTELLI, 1983, p. 30). Kenney (1984, p. XXXVI) aponta que nesses dois exemplos há uma combinação entre cenário idílio, ensinamento moral e ensinamento utilitário, todos relacionados à horta. No entanto, as descrições possuem várias diferenças, como já foi apontado pela maioria dos críticos o que poderia então caracterizar uma tentativa de opor-se a Virgílio.

As semelhanças entre Moretum e as Geórgicas não se limitam a apenas esses trechos. Em outros momentos há, nas Geórgicas, recomendações contrárias ao que Símulo faz. Por exemplo, Símulo passa os dias em que não pode trabalhar no campo cuidando de sua horta (vv. 66-68). As razões dadas para esse impedimento são tanto a chuva quanto um feriado religioso. Na Geórgica 1 (vv. 299-310), recomenda-se que, quando houver tempo ruim, o dia deve ser utilizado para outras atividades e descanso; na Geórgica 2 (vv. 527-531), é dito que os feriados religiosos devem ser aproveitados para lazer.

Há também cenas parecidas com as narradas no poema do Apêndice Virgiliano. A Geórgica 1 (vv. 288-296) mostra que algumas tarefas devem ser feitas à noite ou no início do dia. É citado, como exemplo, um homem que trabalha à noite, enquanto sua mulher o acompanha em outras atividades e ao mesmo tempo canta, em uma cena semelhante à de Símulo e Cíbale. Nesse caso, parece que a rápida cena descrita por Virgílio é desenvolvida mais detalhadamente em Moretum.

Em relação à obra Eneida, é possível perceber a construção de um personagem que é, contra todas as expectativas, chamado de herói (v. 59) ${ }^{8}$. Símulo não possui atributos heroicos e

\footnotetext{
7 Por ex., os próprios Perutelli (1938, p. 30) e Kenney (1984, pp. XXXVI-XXXVII).

${ }^{8} \mathrm{Em}$ três outros momentos da poesia latina as palavras prouidus heros são usadas na mesma posição do hexâmetro, todas em Estácio (Tebaida 4, v. 197 e 8, v. 681; Aquileida 1, v. 698).
} 
não está exposto a nenhuma situação comum a heróis, mas, mesmo assim, está envolvido em uma batalha: aquela travada contra a falta de alimento .

No fim, quando a fome não é mais um problema, Símulo se prepara para trabalhar. $\mathrm{Na}$ descrição de seu traje, são utilizados os termos ocrea e galerum (v. 120, "greva" e "capa”, respectivamente). Essas duas palavras são utilizadas na Eneida, quando pessoas se preparam para a guerra (7, v. 634; 8, v. 624; e 7, v. 688). Ambas referem-se a equipamentos para batalha, um assunto épico. Como o autor as emprega no momento em que Símulo se veste, temos aqui uma possível sátira das cenas de preparação para uma batalha. Por outro lado, talvez o autor tente elevar o dever do homem simples, unindo trabalhos no campo às guerras ${ }^{10}$.

Entre os críticos mais atuais (HORSFALL, 2001; HÖSCHELE, 2005), a tendência é ver Moretum como uma paródia de poesia épica, devido em parte à contínua utilização de palavras que aparecem em contextos épicos ${ }^{11}$. No entanto, como bem lembra Perutelli (1983, p. 30), não podemos nos limitar a interpretar o poema como apenas uma paródia.

\footnotetext{
${ }^{9}$ Kenney (1984, p. 51) aponta que a ênfase na batalha contra a fome acentua o tom de paródia do gênero épico, colocando Símulo como um herói que deve guerrear contra ela, sendo que sua vida é realmente uma luta para sobreviver. Höschele (2005, p. 249) lembra também um conselho dado por Odisseu a Aquiles, já apontado por outros críticos (como Kenney, 1984, e Philip Hardie, em nota oral): não deixar que os soldados lutem sem comer (Iliada 19, vv. 154-170).

10 A visão humorística de um homem simples e pobre não é a única possível. Evandro, que oferece sua modesta casa para Eneias, não é diminuído por ser alguém simples (Eneida 8, vv. 360-369). Também na Geórgica 1 armas são usadas como metáfora para instrumentos agrícolas: dicendum et, quae sint duris agrestibus arma, / quis sine nec potuere seri nec surgere messes (vv. 160-161, "devo também dizer quais sejam as armas para os duros pastores, sem as quais as colheitas não poderiam nem ser plantadas nem crescer") (HÖSCHELE, 2005, p. 250). Todas as traduções fornecidas para passagens citadas em latim são de nossa autoria.

11 Além da já citada utilização do termo prouidus heros, podemos dar como exemplo o verbo condo (v. 122, "esconder", "enterrar") no desfecho do poema, usado também no fim da Eneida (12, vv. 950-951), quando Eneias enfia sua espada em Turno; e a descrição do galo como excubitor (v. 2, "sentinela"), termo militar. É preciso notar, porém, que palavras associadas ao mundo bucólico também são utilizadas em obras épicas. A descrição de Nestor

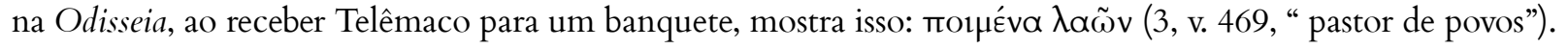


Outro autor que se mostra extremamente importante para uma melhor compreensão de Moretum é Ovídio. O contexto em que Símulo se encontra evoca algumas das cenas de theoxenia narradas nas Metamorfoses (8, vv. 624-724) e nos Fastos (4, vv. 505-562; 5, vv. 493-544), mas novamente há um grande diferencial: Símulo não é agraciado com a visita de deuses, que aparecem, no máximo, como metonímias para as coisas utilizadas em sua manhã.

Como podemos ver através dos fragmentos que sobreviveram, desde o poema Hécale, de Calímaco, alguns elementos são revisitados nas cenas em que pessoas humildes e heróis ou deuses se encontram ${ }^{12}$. Esse enquadramento segue a prática alexandrina de mostrar o herói em cenas de vida cotidiana - o que por si só já remete ao contexto em que Símulo é descrito.

Escolhemos para uma breve demonstração das semelhanças entre o poema Moretum e cenas de theoxenia em Ovídio o episódio sobre Hirieu (Fastos 5). Símulo é um camponês pobre, dono de uma pequena propriedade (v. 3, exigui cultor agri, "agricultor de terra pequena"), isolado da sociedade (sua única companhia é Cíbale). A descrição de Hirieu utiliza palavras semelhantes: senex Hyrieus, angusti cultor agelli (5, v. 499, "o velho Hirieu, agricultor de humilde campinho") (HÖSCHELE, 2005, p. 259).

A casa em que Hirieu recebe os deuses Júpiter, Netuno e Mercúrio é simples e cheia de fumaça (vv. 505, 519-520), assim como a do poema Moretum (vv. 107-108). Tanto Símulo (Moretum, vv. 10-12) quanto Hirieu (Fastos 5, vv. 506-510) têm como primeira ação atiçar com sopros o fogo que quase se apagara. Em seguida, Hirieu dá continuidade à refeição que estava

\footnotetext{
${ }^{12}$ Hécale oferece uma refeição ao herói (fr. 248-251), semelhante à que mulheres fazem para pastores (fr. 251). Uma diferença é que Hécale não possuiria uma origem simples, já que o fragmento 254 pode ser considerado parte de uma fala da personagem sobre seu passado. De qualquer modo, sua realidade no momento em que encontra Teseu é semelhante à de Símulo, pois ela é descrita com acessórios de pastor, como um chapéu e um cajado (fr. 292).
} 
adiantada, sendo que uma das panelas contém holus (Fastos 5, vv. 509-510), planta presente na horta de Símulo (Moretum, v. 71).

As personagens Símulo e Hirieu são parecidas em relação a seu trabalho, situação social e moradia, e suas ações assemelham-se (o acender do fogo, o preparo de uma refeição). Apesar das semelhanças, Símulo não recebe nenhum visitante ou deus em sua casa.

A solidão de Símulo e Hirieu é uma ideia interessante, quando consideramos que o estado de isolamento do homem do campo também em outros gêneros é apresentado como um estilo de vida mais próximo do divino. Por exemplo, nas Bucólicas de Virgílio ou mesmo nos Idílios de Teócrito há grande interação entre pastores e deuses. Como diz Halperin (1983, pp. 96-99), esse estado próximo da esfera divina faz com que os próprios pastores, às vezes, possuam uma aura religiosa, como podemos ver nas histórias de Orfeu, Dáfnis e Hesíodo.

Também nas cenas de theoxenia vemos um desdobramento disso, afinal, é um homem rústico e isolado que recebe um deus ou herói. O casal Filemon e Baucis, após bem receberem os deuses Júpiter e Mercúrio, viram sacerdotes e, depois de sua morte, árvores sagradas para os locais (Metamorfoses 8). Símulo possui os requisitos para ser agraciado por uma aparição divina, mas ela não acontece. Como existe em Moretum uma tendência à descrição mais fiel, objetiva, dos acontecimentos, faz sentido que essa expectativa seja quebrada. A vida pacata de Símulo é mais dura do que a representada em outras obras literárias - receber uma ajuda divina direta iria contra a lógica da descrição de uma vida sofrida e de trabalho13.

\footnotetext{
${ }^{13} \mathrm{O}$ que vemos em Moretum lembra a abordagem utilizada em um epigrama de Leônidas de Tarento (Antologia Palatina 7.736) (PERUTELLI, 1983, pp. 20-21), no qual a voz poética diz que um homem pobre não deve se preocupar com a vida simples que tem, mesmo se possuir apenas uma pequena cabana com um pequeno fogo e alimentos simples.
} 
Outros intertextos poderiam ainda apontar mais questões que permanecem em aberto em relação ao poema. Catão (De agricultura, vv. 74-76), por exemplo, cita que o método de cozimento de um pão sem levedura embaixo da terra é antigo. Nos Fastos (4, vv. 367-372), quando Erato recebe a pergunta de por que as pessoas ainda usam o moretum em honra a Cibele, ela responde que é para que a deusa se lembre desse antigo prato, com o qual os maiores (“antepassados”, “antigos”) sobreviveram no passado. Apesar disso, não é claro se Símulo representa um romano antigo ou se esses costumes permaneceram em uso no ambiente campestre.

Essa incerteza se dá em grande parte pela vagueza que o poema possui em relação ao seu contexto. Muito enfoque é dado ao presente das ações físicas de Símulo e pouco (ou quase nenhum) para seus pensamentos ou mesmo para a sua situação como um todo. A narrativa se mostra extremamente sensorial, contando, inclusive, com imagens que claramente remetem a um conteúdo sexual14.

Horsfall (2001, p. 305) defende que, como o moretum era um prato popular, feito a partir de uma mistura de vários ingredientes, é possível que essa seja uma metáfora para o que o autor do poema tenta fazer. Os diferentes ingredientes representam os diferentes tipos de poesia ou os vários autores que inspiraram esse poema.

A emblemática expressão e pluribus unum é um bom resumo do conceito do moretum: um prato que tem como ponto de partida variados ingredientes e que, no fim, vira uma só pasta, que será consumida imediatamente por uma só pessoa ${ }^{15}$. Do mesmo modo funciona o poema: a partir de diferentes retalhos literários, é criado um breve poema uno.

\footnotetext{
${ }^{14} \mathrm{O}$ próprio uso de um pilão em uma cavidade redonda já na antiguidade aparece como uma metáfora para a penetração sexual (HÖSCHELE, 2005, p. 255).

${ }^{15} \mathrm{O}$ poema não menciona se Cíbale chega a comer junto ou após Símulo, o que nos deixa inclinados a considerar que isso não ocorre.
} 


\section{Sobre a tradução}

Apresentaremos a seguir uma tradução do poema Moretum em "hexâmetro dactílico" português. Seguimos, como explica Gonçalves (2016, p. 187) sobre sua tradução dos hexâmetros de Lucrécio,

(...) um modelo de hexâmetro datílico português que superasse o engessamento do hexâmetro inflexível de Carlos Alberto Nunes, baseado em acentos fixos nas sílabas 1, 4, 7, 10, 13 e 16, visando um hexâmetro como que no meio do caminho entre aquele possível em uma língua que não dispõe de sílabas longas e breves como elemento fonológico estrutural, como é o caso do português, mas que flexibilizasse o rigor do isossilabismo de Nunes ao permitir uma ou duas sílabas não marcadas (átonas, ou não, a depender da performance) entre cada uma das suas sílabas marcadas por acento, emulando a flexibilidade do hexâmetro latino.

Assim, ao invés de seguir o modelo uniforme proposto por Carlos Alberto Nunes, que vê como obrigatória a presença de duas sílabas átonas entre cada tônica (trabalhando sempre com um pé que emularia o dáctilo no latim), pretendemos aqui seguir a ideia exposta pelo tradutor Rodrigo Gonçalves (ibid.), que permite também a presença de apenas uma sílaba átona entre cada tônica (aproximando-se da ideia de um pé espondeu no latim). Essa maior flexibilidade ajuda a dar mais sonoridade ao texto, no sentido em que ele não terá um ritmo monótono, mas sim que pode variar consideravelmente.

Nessa proposta, destacamos ainda mais uma possibilidade, a de não iniciar o verso necessariamente com uma sílaba tônica. Caso inicie com uma átona, a sílaba deve ser seguida por uma ou duas átonas, fechando assim um pé composto por duas ou três átonas, que serão obrigatoriamente seguidas por um pé que inicie com sílaba tônica, como é o esperado no restante do verso. Acreditamos que essa possibilidade funciona bem no momento de leitura do 
texto, pois o início do verso é uma posição normalmente enfatizada no momento de oralização do texto.

Como o texto de Moretum possui algumas particularidades, buscamos em nossa tradução evocá-las quando possível. Podemos citar como exemplo o início do poema (vv. 1-18) e a ausência de enjambements, o que nos levou a buscar ao máximo manter a correspondência entre os versos do texto em latim e os do texto em português. A utilização de um metro maior como o hexâmetro dactílico em língua portuguesa se mostrou produtiva para esse cuidado.

É notável ainda a presença em todo o poema de palavras normalmente usadas em poemas épicos, com especial destaque para o desfecho de Moretum (vv. 119-122). Buscamos destacar isso através da utilização de alguns vocábulos que talvez pareçam estranhos para o contexto de Símulo, mas justamente porque o mesmo ocorre no latim.

Como exemplo, podemos refletir brevemente sobre o verso 121: sub inga parentis cogit lorata iuuencos (por nós traduzido como “obedientes bois convoca sob jugo de loro"). O verbo cogo tem como um de seus possíveis significados "to drive together, round up (cattle, etc.)"16 (OLD, 1). No entanto, há também a definição "to collect (men, ships) in order to make an army, fleet, etc.; to recruit, raise (an army, fleet, or other force)"17 (OLD, 3). Se o primeiro significado é o que melhor se encaixa no contexto, afinal, são citados bois e Símulo é, sem dúvida, um homem que irá trabalhar em suas plantações, ao mesmo tempo existe uma preocupação do autor em utilizar vocábulos específicos da tradição épica. A escolha do verbo cogo não parece ser aleatória, e sim mais um modo de aproximar o prouidus heros Símulo de um herói clássico.

\footnotetext{
16 "Conduzir juntos, emparelhar (gado etc.)".

17 "Reunir (homens, navios) para fazer um exército, frota etc.; recrutar, levantar (um exército, uma frota ou outra força)".
} 
Aproveitamos o verso 121 para também destacar o uso de um hapax legomenon: o adjetivo loratus (“fitted or bound with straps"18, OLD). Traduzimos por uma palavra já existente no português, "loro", mas que com certeza trará ao leitor desacostumado com o cotidiano campestre um estranhamento, já que seu uso na língua cotidiana ou literária atual não é amplo.

Passemos ao texto latino e à tradução.

\section{Moretum}

Seguiremos a edição proposta por Kenney (CLAUSEN, 1966). No entanto, como a instabilidade textual dos poemas do Appendix Vergiliana é grande e atualmente ainda é uma das principais questões sobre a coletânea, optamos por confrontar através de notas algumas das edições de outros críticos, de modo que o leitor tenha diante de si um pouco da complexidade do poema.

\section{Texto latino:}

\section{MORETUM}

Iam nox hibernas bis quinque peregerat horas excubitorque diem cantu praedixerat ales, Simulus exigui cultor cum rusticus agri, tristia uenturae metuens ieiunia lucis,

05 membra leuat uili sensim demissa grabato sollicitaque manu tenebras explorat inertes uestigatque focum, laesus quem denique sensit. paruulus exusto remanebat stipite fomes ${ }^{19}$ et cinis obductae celabat lumina prunae;

\footnotetext{
18 "Equipado ou amarrado com tiras".

19 Fairclough (1918): fumus ("pouca fumaça restava no tronco já exaurido").
} 
admouet his pronam summissa fronte lucernam

et producit acu stuppas umore carentis, excitat et crebris languentem flatibus ignem. tandem concepto, sed wix, fulgore recedit ${ }^{20}$ oppositaque manu lumen defendit ab aura

15 et reserat †clausae qua peruidet ostia clauis.21 fusus erat terra frumenti pauper aceruus: hinc sibi depromit quantum mensura patebat, quae bis in octonas excurrit pondere libras. inde abit adsistitque molae paruaque tabella,

20 quam fixam paries illos seruabat in usus, lumina fida locat; geminos tunc ueste lacertos liberat et cinctus willosae tergore 22 caprae peruerrit cauda silices gremiumque molarum. aduocat inde manus operi, partitus utroque:

25 laena ministerio, dextra est intenta labori. haec rotat adsiduum gyris et concitat orbem (tunsa Ceres silicum rapido decurrit ab ictu), interdum fessae succedit laeua sorori alternatque uices. modo rustica carmina cantat agrestique suum solatur noce laborem,

20 Ribbeck (1868): se lux fulgore recepit ("por fim, tendo a flama acendido, a luz se recupera"); Ribbeck (1895): tenebrae fulgore recedunt ("por fim, tendo a flama acendido, as trevas se afastam").

${ }_{21}$ Ribbeck (1868): et reserat casulae quae peruidet ostia claui ("e destrava as portas da casa com chave, que explora"); Ribbeck (1895): et reserat clausam qua peruidet ostia claui ("e abre com chave o refúgio, onde examina as portas"); Fairclough (1918): et reserat casulae, quae peruidet, ostia clauis ("e uma chave destrava as portas do abrigo, que observa”); Salvatore (1960): et reserat clausae quae peruidet ostia clauis (como a maioria das edições interpreta o adjetivo clausus como um substantivo (ver comentário de Kenney (CLAUSEN, 1966) sobre o verso) indicando um local fechado, o sentido é o mesmo do latim proposto por Fairclough (1918)); Perutelli (1983) e Salvatore (1997): et reserat clausae qua peruidet ostia claui ("e abre as portas do abrigo com chave, por onde investiga"); Kenney (1984): et reserat clausae qua peruidet ostia cellae ("e abre as portas do abrigo fechado, por onde investiga"); Laudani (2004): et reserat casulae quam peruidet ostia claui ("e destrava com chave as portas do abrigo, que observa").

22 Ribbeck (1868, 1895): tegmine (o sentido das palavras tegmen e tergus é muito semelhante, sendo uma possível diferença o fato de que tegmen dá uma ideia mais abstrata de um material que cobre algo, enquanto tergus é mais específico para uma cobertura de pele animal, raramente humana (OLD)). 
interdum clamat Scybalen. erat unica custos, Afra genus, tota patriam testante figura, torta comam labroque tumens et fusca colore, pectore lata, iacens mammis, compressior aluo,

35 cruribus exilis, spatiosa prodiga planta ${ }^{23}$. hanc uocat atque arsura focis imponere ligna imperat et flamma gelidos adolere liquores. postquam impleuit opus iustum ${ }^{24}$ uersatile finem, transfert inde manu fusas ${ }^{25}$ in cribra farinas

40 et quatit; ac remanent26 summo purgamina dorso, subsidit sincera foraminibusque liquatur emundata Ceres. leui tum protinus illam componit tabula, tepidas super ingerit undas, contrahit admixtos nunc 27 fontes atque farinas,

45 transuersat durata manu liquidoque coacta ${ }^{28}$, interdum grumos spargit sale. iamque subactum leuat opus palmisque suum dilatat in orbem et notat impressis aequo discrimine quadris. infert inde foco (Scybale mundauerat aptum

50 ante locum) testisque tegit, super aggerat ignis. dumque suas peragit Vulcanus Vestaque partes, Simulus interea uacua non cessat in hora, uerum aliam sibi quaerit opem, neu sola palato sit non grata Ceres, quas iungat comparat escas. non illi suspensa focum carnaria iuxta

\footnotetext{
23 Ribbeck (1868, 1895) e Fairclough (1918) inserem um verso a mais, seguindo códice dos séculos XII-XIII: continuis rimis calcanea scissa rigebant ("calcanhares lanhados mantinham contínuas fissuras").

${ }^{24}$ Ribbeck (1868): iusto ("quando a versátil máquina encheu justamente o limite").

${ }_{25}$ Fairclough (1918): tusas (“as farinhas batidas”).

26 Kenney (1984): atra manent ("impurezas pretas ficam em cima").

27 Ribbeck (1868): tum ("então"); Ribbeck (1895): nuce (“com noz").

${ }_{28}$ Ribbeck (1895), Fairclough (1918): coacto ("remexe a farinha e os sucos endurecidos com líquido coalhado usando a mão"); Ribbeck (1868): transuersa duratque manu liquidoque coacto ("e endurece com líquido coalhado usando a mão, que atravessa”).
} 
durati sale terga suis ftruncique nacabant ${ }^{29}$,

traiectus medium sparto sed caseus orbem

et uetus adstricti fascis pendebat anethi:

ergo aliam molitur opem sibi prouidos heros ${ }^{30}$.

60 hortus erat iunctus casulae, quem uimina pauca

et calamo rediuina leui munibat harundo,

exiguus spatio, uariis sed fertilis herbis.

nil illi deerat quod pauperis exigit usus;

interdum locuples a paupere plura petebat.

65 nec sumptus ferat ullius 31 opus sed regula curae 32 :

si quando uacuum casula pluuiaeue tenebant

festaue lux, si forte labor cessabat aratri,

horti opus illud erat. uarias disponere plantas

norat et occultae committere semina terrae

70 uicinosque apte circa33 summittere 34 riuos.

hic holus, hic late fundentes bracchia betae

fecundusque rumex maluaeque inulaeque uirebant,

hic siser et nomen capiti debentia porra ${ }^{35}$

grataque nobilium requies lactuca ciborum,

$75 \quad$.........36 crescitque in acumina radix

et grauis in latum dimissa cucurbita uentrem.

uerum hic non domini (quis enim contractior illo?)

\footnotetext{
29 Perutelli (1983): grauabant ("pesavam").

30 Ribbeck $(1868,1895)$ : prouidus herbis ("logo o prudente assume um outro trabalho com ervas").

31 Salvatore (1960): ullus ("nenhum excessivo trabalho havia").

32 Ribbeck $(1868,1895)$ : nec sumptus erat illud opus sed recula curae ("nem custoso era esse trabalho, só um pouco de zelo"). Kenney (1984): nec sumptus ullius erat sed recula curae ("nem havia gasto de alguma coisa, só um pouco de zelo").

33 Ribbeck (1868): apta cura ("e a restringir os vizinhos rios com o cuidado adequado"); Ribbeck (1895): apte curuans ("e restringir os rios vizinhos curvando adequadamente"); Salvatore (1960, 1997): apte cura ("e a restringir com cuidado os rios vizinhos adequadamente").

${ }^{34}$ Laudani (2004): immitere ("direcionar").

35 Ribbeck $(1868,1895)$ e Fairclough (1918) inserem mais um verso, seguindo manuscrito do século XV: hic etiam nocuum capiti gelidumque papauer ("aqui também um perigo à cabeça, gelada papoula").

36 Salvatore (1960) sugere a emenda: hic serpit cucumis ("aqui pepino rasteja”).
} 
sed populi prouentus erat, nonisque diebus

uenalis umero fasces portabat in urbem,

80 inde domum ceruice leuis, grauis aere redibat

uix umquam urbani comitatus merce macelli:

cepa rubens sectique famem domat area porri

quaeque trahunt acri uultus nasturtia morsu

intibaque et Venerem reuocans eruca morantem.

85 tum quoque tale aliquid meditans intrauerat hortum;

ac primum leuiter digitis tellure refossa

quattuor educit cum spissis alia fibris,

inde comas apii graciles rutamque rigentem

uellit et exiguo coriandra trementia filo.

90 haec ubi collegit, laetum consedit ${ }^{37}$ ad ignem

et clara famulam poscit mortaria noce.

singula tum capitum nodoso corpore 38 nudat

et summis spoliat coriis contemptaque passim

spargit humi atque abicit; tseruatum $^{39}$ gramine bulbum ${ }^{40}$

95 tinguit aqua lapidisque cauum demittit in orbem.

his salis inspargit micas, sale durus adeso $0^{41}$

caseus adicitur, dictas ${ }^{42}$ super ingerit herbas,

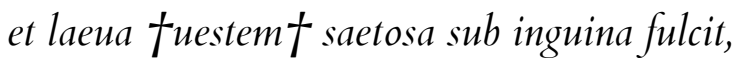

dextera pistillo primum fragrantia mollit

100 alia, tum pariter mixto terit omnia suco.

it manus in gyrum: paulatim singula uires

deperdunt proprias, color est e pluribus unus,

nec totus uiridis, quia lactea frusta repugnant,

nec de lacte nitens, quia tot uariatur ab herbis.

37 Salvatore (1997), Laudani (2004): considit (“senta”).

38 Ribbeck (1868, 1895), Fairclough (1918): cortice ("de casca nodosa").

${ }^{39}$ Laudani (2004): seruato ("com grama protetora”).

40 Ribbeck $(1868,1895)$ : in germine bulbum ("o bulbo em broto").

${ }^{41}$ Salvatore (1997): adhaeso ("com sal grudado").

42 Kenney (1984), Salvatore (1997): lectas (“ervas colhidas"). 
105 saepe uiri nares acer iaculatur apertas

spiritus et simo damnat sua prandia uultu, saepe manu summa lacrimantia lumina terget immeritoque furens dicit convicia fumo. procedebat opus; nec iam salebrosus, ut ante,

110 sed gravior lentos ibat pistillus in orbis.

ergo Palladii guttas instillat oliui

exiguique super uires infundit aceti

atque iterum commiscet opus mixtumque retractat.

tum demum digitis mortaria tota duobus

115 circuit inque globum distantia contrahit unum, constet ut effecti species nomenque moreti. eruit interea Scybale quoque sedula panem, quem laetus ${ }^{43}$ recipit manibus, pulsoque timore iam famis inque diem securus Simulus illam

120 ambit crura ocreis paribus tectusque galero sub inga parentis cogit lorata iumencos atque agit in segetes et terrae condit aratrum.

\section{Tradução}

\section{MORETO}

Quando a noite fizera dez das horas de inverno e o sentinela alado o dia indicara com canto, Símulo, rústico agricultor de terra pequena, tendo medo dos tristes jejuns que viriam com o dia,

5 soltos membros levanta aos poucos da cama modesta, com ansiosa mão explora os escuros inertes, busca o fogo até que por fim o sentiu, machucado. Pouca madeira restava do tronco já exaurido

\footnotetext{
43 Ribbeck (1868): lautis (“que ele recebe com mãos lavadas”).
} 
e escondia a cinza a luz da brasa coberta.

10 Aproxima da fronte abaixada a lucerna pendente e produz estopas de lã com agulha, sem óleo, com repetidos sopros incita a chama cansada.

Tendo a flama acendido com dificuldade, retorna e defende, com a mão oposta, a luz de uma brisa,

15 e uma chave destrava as portas que avista fechadas.

Pobre monte de grãos espalhado fora na terra: tira dali para si o quanto mostrava a medida, que em duas vezes o peso de oito libras excede. Sai então e vai para a mó e em tábua pequena,

20 que a parede mantinha fixa para esse uso, deixa as luzes constantes; assim os braços da veste desengata e envolto com pele de cabra lanosa varre com a cauda as pedras e o interior do moinho.

Chama então as mãos ao trabalho, em dois repartido:

25 auxilia a esquerda, a direita assume a tarefa.

Essa gira constante em círculo, e o orbe agiliza (Ceres moída corre depressa das pedras com o impacto), sobrepõe a esquerda às vezes à irmã fatigada, alternando a função. Já canta rústicos versos

30 e consola com voz agreste a sua tarefa.

Chama às vezes Cíbale. Era sozinha a vigia, de africana origem, com a forma a pátria provando: crespo cabelo, cheia nos lábios e escura na pele; farta no peito, mamas caídas, cintura delgada,

35 com pequenas pernas, pés enormes e longos. Insta por ela e que lenhas no ardor do fogo coloque determina e que queime líquidos frescos na chama. Quando a versátil máquina encheu o justo limite, as espalhadas farinhas transfere com a mão à peneira 
40 e balança. Ficam na parte de cima impurezas, passa o purificado e escorre pelos buracos refinada Ceres. Então com leveza em seguida a junta na tábua, em cima mornas águas derrama, incorpora a farinha e os sucos já misturados,

45 endurecidos e densos com líquido, e mão movimenta, grumos de sal às vezes esparge. E agora o trabalho remexido leva e com as palmas estende em seu disco, assinala igual divisão com quadrinhos marcados. Passa então para o fogo (limpara Cíbale a justa

50 parte primeiro) e cobre com pote, a chama põe sobre. Vesta e Vulcano assim executam seus afazeres. Símulo, enquanto isso, não para em hora vazia. Certo um outro trabalho procura: ao palato sozinha Ceres não é agradável - alguma comida procura.

55 Não há ali suspensas carnes junto do fogo, lombos de porco e pés com sal endurecidos faltavam, mas um queijo furado no meio do orbe por junco e um antigo feixe de endrão amarrado pendiam. Logo o prudente herói assume um outro trabalho.

60 Junto da casa havia uma horta, que defendiam poucas vergas e antigas vigas com cálamo leve, um pequeno espaço, com férteis e múltiplas ervas. O que exigiam os usos do pobre ali não faltava; um abonado às vezes pedia mais coisas do pobre.

65 Seu trabalho não era excessivo, mas régua de esforço: se na casa o mantinham desocupado ou as chuvas ou um festivo dia, se o esforço do arado cessava, era o trabalho na horta. Várias plantas sabia ordenar e juntar sementes da terra coberta

70 e restringir no entorno os rios vizinhos de acordo. 
Há aqui verdes, há ramos de acelga espalhados, fértil labaça e malvas e ênulas esverdeavam.

Há aqui um alho, o que deve o nome à cabeça, e cherívia e agradável alface, descanso das nobres comidas.

e pesada abóbora, em grande ventre espalhada.

Certo que aqui não era do dono (pois quem mais modesto?)

mas do povo a colheita, pois ele toda semana

para vender na cidade levava farnéis em seu ombro.

80 Leve nas costas voltava à casa, com enormes moedas, poucas vezes por bem do mercado da urbe assistido, roxa cebola e parte do alho-poró, que alimenta, e mastruços, que trazem expressão de amarga mordida, e chicória e eruca, que anula a demora de Vênus.

85 Logo entrara na horta, assim também meditando, e por primeiro com dedos leves da terra mexida quatro dos alhos de espessas raízes ele retira e então finas folhagens de aipo e rígida arruda colhe e coentros que tremem com suas hastes pequenas.

90 Quando essas coisas colheu, sentou com fogo animado e então pede em clara voz tigela à ajudante.

Logo desnuda cada cabeça de corpo nodoso, tira os fins da casca e às vezes porções desprezadas joga na terra e descarta. O bulbo com grama guardado

95 na água mergulha e coloca em orbe profunda de pedra. Grumos de sal esparge e um queijo com sal ressecado é somado; coloca em cima as ervas já ditas e com a esquerda sustenta a veste sob ventre peludo com um pilão a direita primeiro amacia moscados

100 alhos, logo esfrega tudo com o suco gerado.

Vão em giro as mãos: aos poucos cada atributo 
próprio perdem, e a cor é uma dentre diversas:

nem é um todo verde, pois partes leitosas resistem;

nem como leite brilha, pois era mudado por ervas.

105 Várias vezes atinge as narinas expostas o cheiro

acre, e condena o seu desjejum com nariz contraído,

várias vezes esfrega com a mão os olhos chorosos,

e furioso com a injusta fumaça insultos resmunga.

Continuava o trabalho, não inconstante como antes,

110 mas mais pesado o lento pilão em círculo ia.

Gotas de azeite de Palas Atena coloca em seguida

e derrama em cima o vigor do parco vinagre

e de novo combina o trabalho. Retira a mistura.

Logo por fim com dois dos seus dedos toda a tigela

115 raspa e junta em uma esfera as partes distantes,

o que condiz com a aparência e o nome do feito moreto.

Enquanto isso Cíbale o pão remove, zelosa,

que ele feliz recebe nas mãos, e com o medo da fome

já afastado, Símulo, nesse dia tranquilo,

120 veste as pernas com par de grevas, com capa trajado

obedientes bois convoca sob jugo de loro,

nas plantações os conduz e na terra insere o arado. 


\section{Referências bibliográficas:}

CHOLMELEY, R. J. (ed.). Theocritus. Idylls. London: George Bell \& Sons, 1909.

CLAUSEN, W. V. et al. Appendix Vergiliana. Oxford: Oxford University Press, 1966.

ELLIS, R. A Bodleian Ms. of Copa, Moretum, and other poems of the Appendix Vergiliana. London: Henry Frowde, 1906.

FAIRCLOUGH, H. R. (trad.). Virgil. Vol. II: Aeneid Books 7-12; Appendix Vergiliana. Cambridge: Loeb Classical Library, 1918.

GONÇALVES, R. "Tradução e ritmo: rêver le vers de Lucrécio". In: Morus - Utopia e Renascimento, Campinas, v. 11, n. 1, 2016, pp. 181-197.

HALPERIN, D. M. Before Pastoral: Theocritus and the Ancient tradition of Bucolic poetry. West Hanover: Yale University, 1983.

HORSFALL, N. “The Moretum decomposed”. In: Classica et Mediaevalia, v. 52, 2001, pp. 303-15.

HÖSCHELE, R. "Moreto-Poetik: das Moretum als intertextuelles Mischgericht”. In: HOLZBERG, N. (ed.). Die “Appendix Vergiliana”: Pseudepigraphen im literarischen Kontext. Classica Moncensia, 30. Tübingen: Gunter Narr Verlag, 2005, pp. 244-269.

KENNEY, E. J. The Ploughman's Lunch, Moretum: a poem ascribed to Virgil. Bristol: Bristol Classical Press, 1984.

LAUDANI, C. Moretum. Nápoles: Loffredo Editore, 2004.

PEIRANO, I. “Constructing the young Virgil: the Catalepton as pseudepigraphic literature”. In: The Rhetoric of the Roman fake: Latin Pseudepigrapha in Context. Cambridge: Cambridge University Press, 2012.

PERUTELLI, A. VIRGÍlLIO. Moretum. Pisa: Giardini Editori e Stampatori, 1983.

RAND, E. K. "Young Virgil's Poetry”. In: Harvard Studies in Classical Philology, Massachusetts, v. 30, 1919, pp. 103-185.

RIBBECK, O. P. "Vergili Maronis Opera”, vol. 4, in: Appendix Vergiliana. Leipzig: Teubner, 1868.

. "Vergili Maronis Opera”, vol. 4, in: Appendix Vergiliana. Leipzig: Teubner, 1895.

SAlVATORE, A. Appendix Vergiliana. Vol. 2. Aug. Taurinorum: In aedibus I. B. Paraviae, 1960. . et al. Appendix Vergiliana. Roma: Typis Officinae Polygraphicae, 1997.

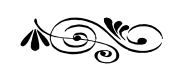

